\title{
Performance Assessment System Development Based on Performance Prism in Social Services
}

\author{
Rui Estrada ${ }^{1}$, Sérgio Sousa ${ }^{2}$, Isabel Lopes ${ }^{2}$, \\ ${ }^{1}$ Department of Production and Systems, University of Minho, Guimarães, Portugal \\ ${ }^{2}$ Department of Production and Systems/ALGORITMI Research Centre, University of Minho, Guimarães, Portugal \\ ${ }^{1}$ rui.a.estrada@gmail.com \\ ${ }^{2}\{$ ilopes/sds\}@dps.uminho.pt
}

\begin{abstract}
This paper aims to study the practical application of Performance Prism in the social services sector. To achieve this, a performance assessment system, based on the Performance Prism model, was developed in a Portuguese private institution of social solidarity.
\end{abstract}

Keywords - EQUASS, performance measurement, performance prism, social services

\section{INTRODUCTION}

The Third Sector consists of a set of civil society organizations that seek to complement public services in areas of education, health and social services [1] and thus, in a logic of proximity and solidarity, seek to respond more effectively to the needs of the Community.

In the last decades, in Portugal, there has been a great growth and renovation of the Third Sector [2], which has resulted in the increase of the number of organizations and, consequently, in the increase of the competition and the level of demand of its customers, financial supporters and the community itself. This scenario was particularly felt in the social services segment, which has strengthened its role in society [1], [2].

This pressure has led organizations to adopt strategies to respond to new demands of their stakeholders and to stand out from other organizations. In this context, organizations have begun to renew their management processes and to monitor organizational performance.

The main motivation for performance monitoring in Third Sector organizations is therefore related to facilitating accountability to their funders and delivering results to stakeholders, while on the other hand, only a small part claims to use this tool to improve their services [3]-[6]. The implementation of a performance assessment system is often accompanied by some limitations associated with the level of complexity of the organizations themselves, risking an increase of bureaucracy [5].

Organizations have shown an increasing interest in developing their quality management systems to continuously improve processes' performance [7]. In addition, this area of research is still at an early stage [5], so there is a need to work on this issue and find solutions to overcome the difficulties experienced by organizations when it comes to managing their performance.

Performance assessment evolution has complemented Quality Management in the Third Sector, because there are emerging models increasingly oriented to a holistic assessment and to the characteristics of this type of organizations.

The Balanced Scorecard [8], for example, was developed considering the private and for-profit organisations, and its adaptation for application in the social sector was already the target of some studies [3], [9], [10]. It is referred to as one of the most widely used multidimensional approaches to performance measurement in the Third Sector [5]. On the other hand, there are few references to Performance Prism (PP) in this activity sector, although this is presented as a comprehensive model and adaptable to any type of organization [11]. PP presents a high level of correlation [12] with EQUASS [13] which is an assessment model specifically developed for the social services sector, thus suggesting that PP is a suitable model to develop a performance assessment system in an organization of the social sector.

The objective of this work is to present a case study describing a practical approach to develop an assessment system based on the PP, that responds to the needs of an organization of the social sector.

The remaining part of this work is organized as follows. Section II presents a literature review on PP model, seeking to know all the necessary steps for its application in an organization. It also presents the state of the art of performance assessment in the social services sector, seeking to identify the most important indicators to be included in the performance assessment of these organizations. Section III presents the practical application and elaborates a proposal of performance assessment system in a Portuguese social solidarity institution. The project took place within a Portuguese organization of the social and solidarity sector. Section IV discusses the result of developed system and the paper finishes with conclusion on section V.

\section{LITERATURE REVIEW}

\section{A. Performance Measurement in social services}

Research in the social services sector has shown difficulties for organizations in implementing and using performance assessment systems, as well as revealing that this process is essentially motivated to be accountable to their funders and continue to receive their funding [5]. 
However, this assessment is limited and is not in line with institutions' actual objectives [4].

For [8], a performance assessment system should always prioritizes the balance between the various types of indicators (e.g. financial and non-financial, process and result, internal and external). In the case of Third Sector organizations, several authors argue that performance measurement should be focused on: a) mission [9], [10], $[14],[15]$; b) the strategy [16]; c) process and outcome indicators [4], [17]. However, there are some difficulties associated with the nature of the organizations themselves, such as: a) a vague and abstract mission; b) lack of a clear strategy with defined objectives; c) difficulty in objectively assessing the impact of their services on beneficiaries as a result of the wide range of external factors influencing the results of their activities, e.g. improving the well-being and people's quality of life [17]-[19].

\section{B. The Performance Prism}

The PP model [11] was designed to be oriented to any sector of activity, encompassing a vast network of relevant stakeholders and also privileging the reciprocal relationship established between them and the organization itself. These characteristics bring PP closer to the reality of social services, making it suitable to develop a performance assessment system for these organizations [12].

The PP model is based on five performance perspectives. Each one can be analysed by answering the following questions:

1.Stakeholder satisfaction - which are organizations' stakeholders and what are their needs and expectations?

2.Contribution of Stakeholders - what are the organization's needs and expectations regarding stakeholders?

3.Strategies - what strategies the organization needs to implement to meet the needs and expectations of stakeholders?

4.Processes - what processes do the organizations need to put into practice so it can execute strategies?

5.Capabilities - what capabilities do we need to ensure to be able to operate our processes?

It is possible to identify in the literature some studies related to the implementation of performance assessment models in the Third Sector, however, the research related to Performance Prism is mainly dedicated to the private and profitable sector [20]-[22], being less developed in the Third Sector.

\section{IMPLEMENTING THE PEFORMANCE PRISM}

The research period had a duration of about 6 months, during which the researcher had a practically exclusive dedication to this project, still performing some functions in the Quality Department of the organization.
Based on the model presented by its creators, a methodology was developed to apply PP in a social services organization, comprising the following phases:

1. Identification of relevant Stakeholders;

2. Definition of the satisfaction and contribution components of each stakeholder;

3. Definition of strategies, processes and capacities oriented to organizational objectives and to satisfaction of the stakeholders. Creation of a Success Map based on existing relationships between processes, strategies and capabilities;

4. Definition of performance indicators.

\section{A. Description of the case study}

The organisation under study is a Portuguese private institution of social solidarity, which develops its social activity in the areas of Childhood, Health and Third Age, being located in a dispersed and increasingly aging community. The organization is certified for quality through the EQUASS Assurance.

The activity of the organization is essentially based on the provision of health care and social, psychological and spiritual support. The fulfilment of its mission is closely linked to support for the family, promoting wellbeing and improving the quality of life of its customers or persons served. The organization has an agreement with the Portuguese Institute of Social Security to host about 170 people under its social responses, and has about 115 employees, being one of the largest employers in the region where it operates. Much of its funding is obtained through public funds, so that the measurement of organizational performance relies mainly on financial indicators for the presentation of results to the financing entities.

Thus, the application of the PP aims to innovate the organizational performance assessment system and to promote continuous improvement of its Quality Management System.

\section{B. The stakeholders of the organization}

The organization has a complex network of stakeholders, which is already identified within its Quality Management System. However, for this work, we chose to use a simplified version of the network, since this does not go against the purpose of the work and facilitates its realization and understanding.

Thus, from the analysis of the institution's activity, four groups of stakeholders were identified: a) customers b) employees; c) community; d) financial and regulatory entities. They were identified by the investigator who leaded the study, based on the documentation of the existing Quality Management System, on the observation of the organization activities and by the interaction with employees and Top Management.

Customers are considered as all individuals who enjoy the services of the organization and pay their monthly contribution. This group integrates both users of 
social responses and their relatives / caregivers. The customer is the main stakeholder of the organization, since all its strategy and activity is directed to support families and improve their well-being and quality of life.

Collaborators include all paid human resources at the service of the organization, including a vast network of functions linked, directly or indirectly, to the quality of services provided and to customer satisfaction.

Within the Community, all entities (individual or collective) that influence or are influenced by the institution's activity, which includes local population and partner entities, are considered. This stakeholder is closely linked to the Customer since it includes potential users that the institution seeks to receive in the future.

The Financial and Regulatory Entities are organizations that financially support the institution's activity and ensure the compliance of its activity with the assumed agreements and legislation.

\section{Satisfaction and Contribution of the Stakeholders}

Once the network of relevant stakeholders has been identified, the respective components of satisfaction and contribution to the organization have been defined. As a result of this research, Table 1 was built.

\section{Strategies, Processes and Capacities}

For this phase of the project the observation by the researcher of the activity of the organization was important, however, the meetings held with Top Management and the technical officials of the institution were also fundamental so that the researcher could better understand its operation. The strategies, processes and capacities defined in this phase were submitted to the approval of these members of the organization.

Firstly, the institution's strategies were defined, aligned with the Quality Policy and with the components of satisfaction and contribution of its stakeholders. The strategies were defined as follows:

1. Increase the efficiency of services provided;

2. Value human resources;

3. Re-qualify equipment and infrastructures;

4. Promote community involvement;

5. Promote financial sustainability; bodies.

6. Act in accordance with funding and regulatory

Then, in alignment with these strategies, the processes and capacities needed to ensure its implementation were defined. Processes and capabilities are represented in the Success Map (Fig. 1).

In the Map of Success, the interactions between strategies, processes and capacities were also illustrated. Even though it is a simplified version, it is possible to observe the complexity of the organization, including strategies that aim to improve the operationalization of processes or capacities necessary for the execution of other strategies.
TABLE 1

SATISFACTION AND CONTRIBUTION OF THE STAKEHOLDERS

\begin{tabular}{|c|c|c|}
\hline Stakeholder & Satisfaction & Contribution \\
\hline \multirow{6}{*}{ Customers } & Satisfy the individual & Opinions and \\
\hline & Heeds or the user & suggestions \\
\hline & Have their voice heard & Loyalty \\
\hline & Dignity and respect & \\
\hline & Likes and interests & Good image \\
\hline & respected & transmission \\
\hline \multirow{6}{*}{ Employees } & Work conditions & Professional skills \\
\hline & Professional qualification & Opinions and \\
\hline & Recoonition & Interest in nrofessional \\
\hline & & development \\
\hline & Justice & \\
\hline & Adequate remuneration & \\
\hline \multirow{7}{*}{ Community } & Ability to respond to the & Good image \\
\hline & needs of the population & transmission \\
\hline & Transparency & Support and active \\
\hline & & participation \\
\hline & Solidity, sustainability & $\begin{array}{l}\text { Supply of goods and } \\
\text { services }\end{array}$ \\
\hline & Loyalty to the region & Skilled labor \\
\hline & Possibility of employment & \\
\hline \multirow{6}{*}{$\begin{array}{l}\text { Financial } \\
\text { and } \\
\text { regulatory } \\
\text { entities }\end{array}$} & $\begin{array}{l}\text { Responding to local } \\
\text { community needs }\end{array}$ & Technical monitoring \\
\hline & Fulfilment of agreements & Adequate and timely \\
\hline & made & funding \\
\hline & accountability & Counselling \\
\hline & & Clarification \\
\hline & & Fair treatment \\
\hline
\end{tabular}

The construction of this Success Map implied a deep reflection within the organization in order to identify and define the appropriate strategies, processes and capacities to fulfill its objectives. This made this phase longer, but it was essential to identify the most important factors influencing the success of the organization.

\section{E. Performance Indicators}

The definition of the performance indicators was based on the type of indicators recommended in the bibliographic review and, following the logic of the PP, which allows monitoring the performance of the organization in terms of its strategies, processes and capacities and the satisfaction of the needs of the stakeholders and their own needs. Thus, a set of performance indicators was sought in order to respect the following requirements:

1. Monitoring the fulfillment of the Mission (improvement of the Quality of Life of the community);

2. Outcome and process indicators;

3. Indicators related to the components of the Success Map (Fig. 1);

4. Indicators to quantify the satisfaction and level of contribution of its stakeholders;

5. Inclusion of financial indicators;

6 . Get balance between various types of performance indicators. 


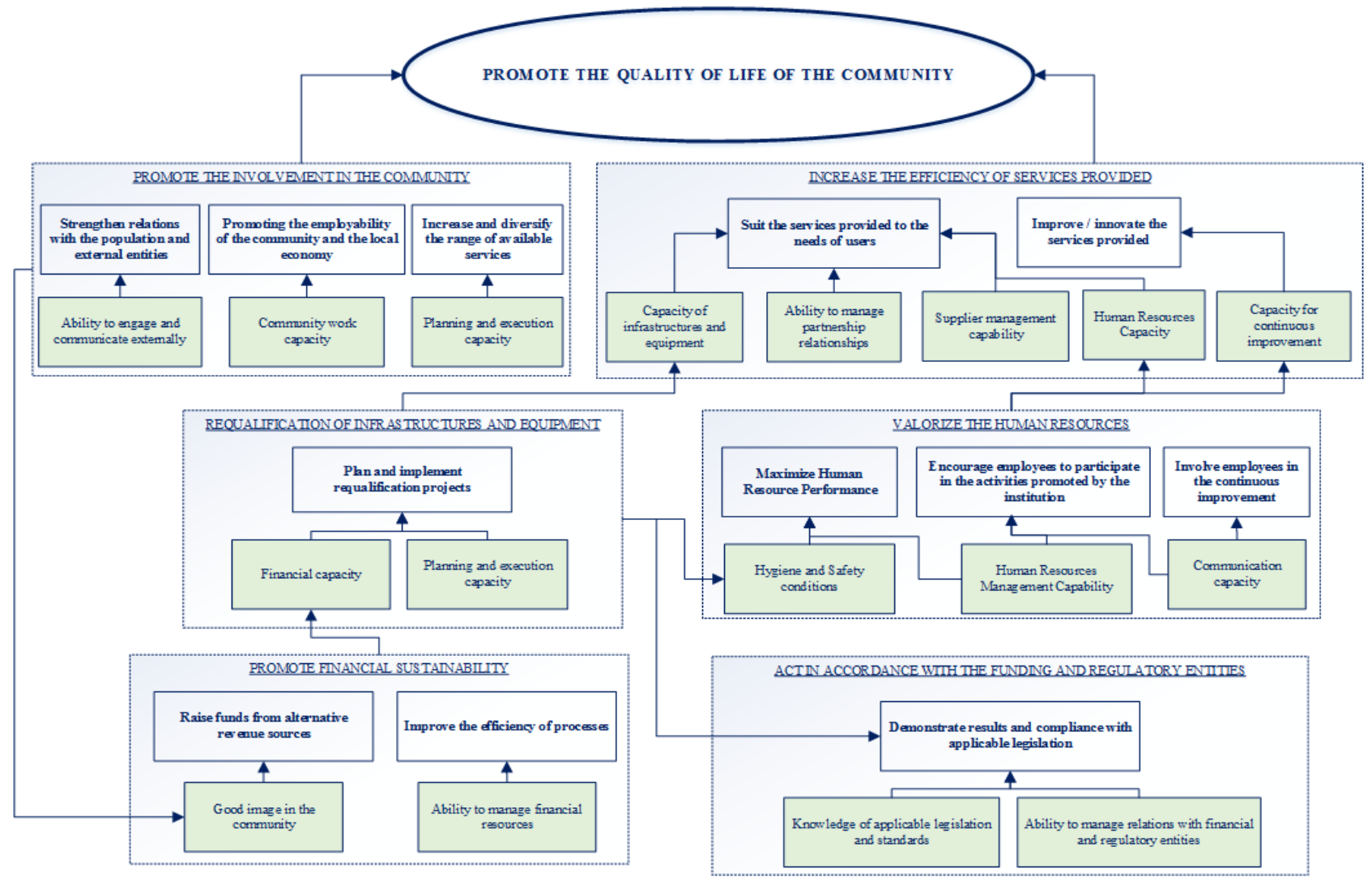

Fig. 1. Success Map

Indicators were defined to consider all components of the Success Map. In a preliminary review, it was found that it would not be relevant to constantly monitor all of these indicators, and that some components of the Success Map could be monitored using the same indicator, so that their number was reduced, resulting in a definition of 3 to 5 indicators for each PP perspective (Table 2).

\section{DISCUSSION OF THE RESULTS}

The work carried out resulted in a set of performance indicators, with which it is intended to generate a global vision of an organization of the social sector. This work used semi-structured interviews, direct observation and records to collect relevant data.

The use of PP as a starting point for the definition of these indicators implied that an in-depth study of the entire activity of the institution was carried out. It was possible to identify the strategies to be adopted to achieve organization's objectives, and which processes and capacities were needed to guarantee the execution of those strategies.

Using PP as the basis for an internal reflection of the organization, and taking into account the Mission and the objectives of the organization, it will be able to use a performance assessment system that responds to their needs. However, the implementation of PP may be associated with considerable resource consumption, such as the need for skilled employees and the time spent in the entire process. In addition, continuous improvement should be a strategic objective at the highest level of the organization [5], otherwise it will not be possible to obtain benefits from this investment.

TABLE 2

PERFORMANCE INDICATORS

\begin{tabular}{ll}
\hline Perspective & Indicator \\
\hline \multirow{3}{*}{$\begin{array}{l}\text { Stakeholders' } \\
\text { satisfaction }\end{array}$} & $\begin{array}{l}\text { Satisfaction rate (for each stakeholder) } \\
\text { Rate of users with improvement of the Quality of } \\
\text { Life Index } \\
\text { Number of customer complaints }\end{array}$ \\
\hline \multirow{3}{*}{ Stakeholders' } & $\begin{array}{l}\text { Participation rate in satisfaction surveys } \\
\text { Number of improvement suggestions }\end{array}$ \\
& $\begin{array}{l}\text { Effectiveness of the Training Plan } \\
\text { Level of professional performance }\end{array}$ \\
\hline \multirow{3}{*}{ Strategies } & $\begin{array}{l}\text { Annual Activity Plan compliance rate } \\
\text { Achievement rate of organizational goals } \\
\text { Effectiveness rate of improvement actions }\end{array}$ \\
\hline Processes & $\begin{array}{l}\text { Number of non-conformities detected in audit or } \\
\text { follow-up report } \\
\text { Number of training hours/ number of planned } \\
\text { training hours } \\
\text { Rate of activities compliance of the users' } \\
\text { individual plans }\end{array}$ \\
& $\begin{array}{l}\text { Financial autonomy } \\
\text { Number of employees / number of required } \\
\text { employees } \\
\text { Level of competences of the established plan / level } \\
\text { of competencies required } \\
\text { Policy effectiveness rate } \\
\text { Assessment of working conditions }\end{array}$ \\
\hline & \\
\hline &
\end{tabular}




\section{CONCLUSION}

This study aimed to study the practical application of PP in the social services sector, complementing research in this area. To achieve this goal, a methodology was used to build a performance assessment system in a social services organization, based on PP perspectives and taking into account the specific characteristics of this activity sector.

It can be concluded from this case study that Performance Prism is a tool that motivates organizations to make an internal reflection of their processes. Through this knowledge, the organization can identify what is important to achieve its objectives and thus define indicators to better control their performance.

Private institutions of social solidarity are quite different from each other, so the indicators presented may not be adequate for another organization. However, these organizations are governed by similar values and principles. The fact that they can be guided by the same Quality benchmark (EQUASS) shows that they have common characteristics. In this way, it is considered that the approach used can be applied to any organization in the social sector, and performance indicators will always have to be defined according to the organizational context. However, the tasks presented in this case study have proved to be a time-consuming and resourceconsuming requiring qualified personnel to be executed. As these additional tasks were not quantified it can be view as a limitation of this work.

It is suggested that this project be continued in two ways: a) to extend the scope of research, applying this approach in other organizations with other types of services; b) focus on the implementation and review phases of the performance appraisal system and assess its influence on the organization's performance and quality culture.

\section{ACKNOWLEDGMENT}

This work has been supported by COMPETE: POCI01-0145-FEDER-007043 and FCT - Fundação para a Ciência e Tecnologia within the Project Scope: UID/CEC/00319/2013.

\section{REFERENCES}

[1] R. C. Franco, S. W. Sokolowski, E. M. H. Hairel, and L. M. Salamon, The portuguese nonprofit sector in comparative perspective. 2005.

[2] C. Quintão, "O Terceiro Sector e a sua renovação em Portugal .," 2, 2011.

[3] D. Greiling, "Balanced scorecard implementation in German non-profit organizations,” Int. J. Product. Perform. Manag., vol. 59, no. 6, pp. 534- 554, 2010.
[4] V. Sillanpää, "Performance measurement in welfare services : a survey of Finnish organisations," Meas. Bus. Excell., vol. 15, no. 4, pp. 62-70, 2011.

[5] C. Moxham, "Understanding third sector performance measurement system design: a literature review," Int. J. Product. Perform. Manag., vol. 63, no. 6, pp. 704-726, 2014.

[6] K. LeRoux and N. S. Wright, "Does Performance Measurement Improve Srategic Decision Making? Findings From a National Survey of Nonprofit Social Servive Agencies," Nonprofit Volunt. Sect. Q., vol. 20, no. 10, pp. $1-17,2010$.

[7] N. F. Melão, S. M. Guia, and M. Amorim, "Quality Management and Excellence in the third sector: examining European Quality in Social Services (EQUASS) in nonprofit social services," Total Qual. Manag. Bus. Excell., 2016.

[8] R. S. Kaplan and D. P. Norton, The Balanced Scorecard: Translating Strategy Into Action. 1996.

[9] E. Kong, "Analysing BSC and IC's usefulness in nonprofit organizations," J. Intellect. Cap., vol. 11, no. 3, pp. 284 304, 2010.

[10] P. R. Niven, Balanced Scorecard step-by-step for government and non-profit agencies. Jonh Wiley \& Sons, Inc., 2003.

[11] A. Neely, C. Adams, and M. Kennerley, The Performance Prism. The Scorecard for Measuring and Managing Business Sucess. Prentice Hall, 2002.

[12] R. Estrada, S. Sousa and I. Lopes, "Performance Prism applicability in the social service sector," in 47th International Conference on Computers \& Industrial Engineering, (accepted) 2017.

[13] EQUASS, "Certificação da Qualidade dos Serviços Sociais - Requisitos," 2012.

[14] B. M. Beamon and B. Balcik, "Performance measurement in humanitarian relief chains," Int. J. Public Sect. Manag., vol. 21, no. 1, pp. 4-25, 2008.

[15] J. Sawhill and D. Williamson, "Measuring what matters in nonprofits," McKinsey Quarterly, 2001. [Online]. Available: http://www.mckinsey.com/industries/socialsector/our-insights/measuring-what-matters-in-nonprofits. [Accessed: 06-May-2016].

[16] T. M. Lam, "Optimisation of performance management for housing services," J. Facil. Manag., vol. 6, no. 3, pp. 226240, 2008.

[17] J. Malley and J.-L. Fernández, "Measuring quality in social care services: theory and practice," Ann. public Coop. Econ., vol. 81, no. 4, pp. 559-582, 2010.

[18] É. F. Pereira, C. S. Teixeira, and A. dos Santos, "Qualidade de vida: abordagens, conceitos e avaliação," Rev. Bras. Educ. Física e Esporte, vol. 26, no. 2, pp. 241-250, 2012.

[19] A. S. Lobo, L. Santos, and S. Gomes, "Nível de dependência e qualidade de vida da população idosa," Rev. Bras. Enferm., vol. 67, no. 6, pp. 913-919, 2014.

[20] A. Neely and C. Adams, "The Performance Prism in action - a case study," no. September, 2002.

[21] M. R. Rendeiro, "Performance Prism: Proposta de Modelo para o setor logístico," MSc thesis, Universidade do Porto, 2014.

[22] R. C. Correia, "Aplicação do Performance Prism como modelo de orientação e monitorizaçao estratégica," MSc thesis, Instituto Superior de Ciências do Trabalho e da Empresa, 2009. 